Fourth International Conference on Sustainable Construction Materials and Technologies http://www.claisse.info/Proceedings.htm

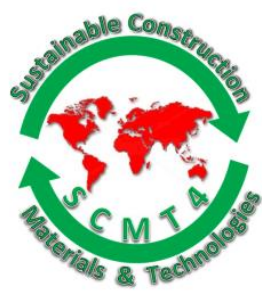

SCMT4

Las Vegas, USA, August 7-11, 2016

\title{
Environmental Emissions in Building Construction - Two Case Studies of Conventional and Pre-Fabricated Construction Methods in Australia
}

\author{
Malindu Sandanayake ${ }^{1 \mathrm{a}}$, Guomin Zhang ${ }^{1 \mathrm{~b}}$, Sujeeva Setunge ${ }^{1 \mathrm{c}}$, and Chun Qing Li ${ }^{1 \mathrm{~d}}$ \\ ${ }^{I}$ Department of Civil, Environmental and Chemical Engineering, RMIT University, Melbourne, Victoria \\ 3001, Australia. ${ }^{1 a}$ Email: 〈malindu.sandanayake@rmit.edu.au>, ${ }^{1 b}$ Email: 〈kevin.zhang@ \\ ${ }^{1 c}$ Email: <sujeeva.setunge@rmit.edu.au>, ${ }^{1 d}$ Email: 〈chunqing.li@rmit.edu.au〉.
}

\begin{abstract}
Emissions at the construction stage seem to be getting a lot of attention in the research area for its relative significance over shorter time spans. Applications of various construction methods are recognised as one of the options to minimise emissions at the construction stage of a building. The focus of this study is to compare emission distribution of different construction methods. Two case studies of conventional and semi pre-fabrication construction methods in Australia are employed to compare this emission variation of adopting different construction methods. It sets a system boundary of embodied emissions from building materials, emissions from construction equipment, transportation of building materials, prefabricated materials and construction waste. Quantitative models are developed to compute both greenhouse gas (GHG) and non-GHG emissions. An impact assessment was also carried out to examine the relative importance of impacts at global, regional and local perspectives. The case study results indicated that adopting pre-fabrication method offers a GHG emission reduction of $1.7 \%$ while an increase of non-GHG direct emissions by 0.9 to $3.5 \%$. Global Warming Potential (GWP) remained the highest impact category for all the perspectives considered, with an overpowering $86.8 \%$ contribution from global perspective. However, this relative importance is reduced to 52\%, with a relative increase in Eutrophication (EP) and Photochemical Oxidant Formation Potential (POFP) up to $21.74 \%$ and $27.14 \%$ at regional and local perspective. Emission increase due to transportation shows a relative increase in POFP potential for pre-fabrication. These results signify that non-GHG emissions should be given importance at regional and local perspective when using pre-fabrication method in construction.
\end{abstract}

\section{INTRODUCTION}

Environmental emissions are one of the most harmful by-products of industry productions (Dimoudi and Tompa, 2008, Sandanayake et al., 2015). Building and construction industry is responsible for a major share of this contribution with studies emphasizing it as one of the seven dominant contributors towards emissions (Mao et al., 2013). Most of the emission studies on buildings have concluded that the use phase of a building is responsible for around $80 \%$ of the emissions while other life cycle stages contribute only for $20 \%$ of the total emissions. This conclusion shifted the research focus towards minimising emissions at the use phase of a building with less concentration given on other stages such as material 
manufacturing and construction stages. However, several other studies attempted to highlight the importance of emissions at the construction stage of a building at an aggregated level (Mao et al., 2013, Guggemos and Horvath, 2005). Emissions at the construction stage of a building can be important to contractors and designers who seek methods to reduce emissions during construction. Especially in Australia, the recently turned down carbon tax, if implemented can be an extra cost burden for contractors on top of satisfying the environmental regulations (Wong et al., 2012). Moreover the significance of other life cycle stages has amplified with the introduction of regulations and policies to enhance the user characteristics of the building. Therefore, evaluation of emissions at the construction stage of a building seems to be a worthwhile research area of focus.

The definition of emissions at the construction stage of a building can vary according to the system boundary of the study (Yan et al., 2010a). A case study conducted in Hong Kong considered six emission sources to estimate emissions at the construction stage (Yan et al., 2010b). It categorised emissions from materials into manufacture and transportation of materials; emissions from equipment into transportation and energy use of equipment and emissions from transportation into transportation of workers and construction waste. A similar study to estimate greenhouse gas (GHG) emissions at construction stage considered off-road combustions, mobile combustions, electricity usage and construction worker emissions as the system boundary (Hong et al., 2015). However, Guggemos and Horvath justified the exclusion of emissions from permanent materials from the construction stage system boundary and proposed it to be an independent stage as the materials manufacturing stage (Guggemos and Horvath, 2006, Guggemos, 2003). Moreover, emissions at the construction stage can incur both GHG and nonGHG emissions due to partial combustion of fuel from mobile and off-road machines used during the construction stage (Frey et al., 2010, Samaras and Zierock, 1995). Therefore, distinguishing a generic system boundary for emission study at the construction stage can be highly debatable.

In order to address the following gaps and complications, the study aims to develop a methodology to estimate GHG and non-GHG emissions at the construction stage of a building for both conventional and pre-fabrication construction methods. These estimated emission results are then used in an impact assessment in order to evaluate the impact based on geographic perspectives (global, regional and local).

\section{METHODOLOGY DESIGN}

Scope and system boundary. It is evident that there is a controversial opinion on the definition of a generic system boundary for emission studies at the construction stage of a building. A substantial system boundary for an emissions study at the construction stage should be able to address the objectives of the study. Therefore, the system boundary of the study is selected to incorporate embodied emissions from construction materials (E1), transportation of building materials (E2), transportation of construction waste and soil (E3), transportation of pre-fabricated materials (E4) and emissions from equipment usage (E5). Figure 1 illustrates the calculation boundary considered for the two case studies.

A major objective of the study is to estimate both GHG and non-GHG emissions at the construction stage. According to the Australian greenhouse gas accounts (AGGA) report, major GHG emissions include carbon dioxide $\left(\mathrm{CO}_{2}\right)$, methane $\left(\mathrm{CH}_{4}\right)$, nitrous oxide $\left(\mathrm{N}_{2} \mathrm{O}\right)$, ozone $\left(\mathrm{O}_{3}\right)$, sulphur hexafluoride $\left(\mathrm{SF}_{6}\right)$ and several other fluorides of carbons. However $\mathrm{CO}_{2}, \mathrm{CH}_{4}$ and $\mathrm{N}_{2} \mathrm{O}$ are more significant at fuel combustion from equipment and vehicles. To establish a common comparative basis both $\mathrm{CH}_{4}$ and $\mathrm{N}_{2} \mathrm{O}$ are converted into $\mathrm{CO}_{2}$ equivalents using Global Warming Potential (GWP) values. Thus herein the GHG emissions in the study refer to $\mathrm{CO}_{2}, \mathrm{CH}_{4}$ and $\mathrm{N}_{2} \mathrm{O}$ emissions. Apart from $\mathrm{GHG}$ emissions, non-GHG emissions such as carbon monoxide $(\mathrm{CO})$, nitrogen oxides $\left(\mathrm{NO}_{\mathrm{x}}\right)$, sulphur dioxides $\left(\mathrm{SO}_{2}\right)$, hydro carbons $(\mathrm{HC})$ and particulate matter (PM) are witnessed due to partial combustion of fuel. Therefore, the study incorporates 


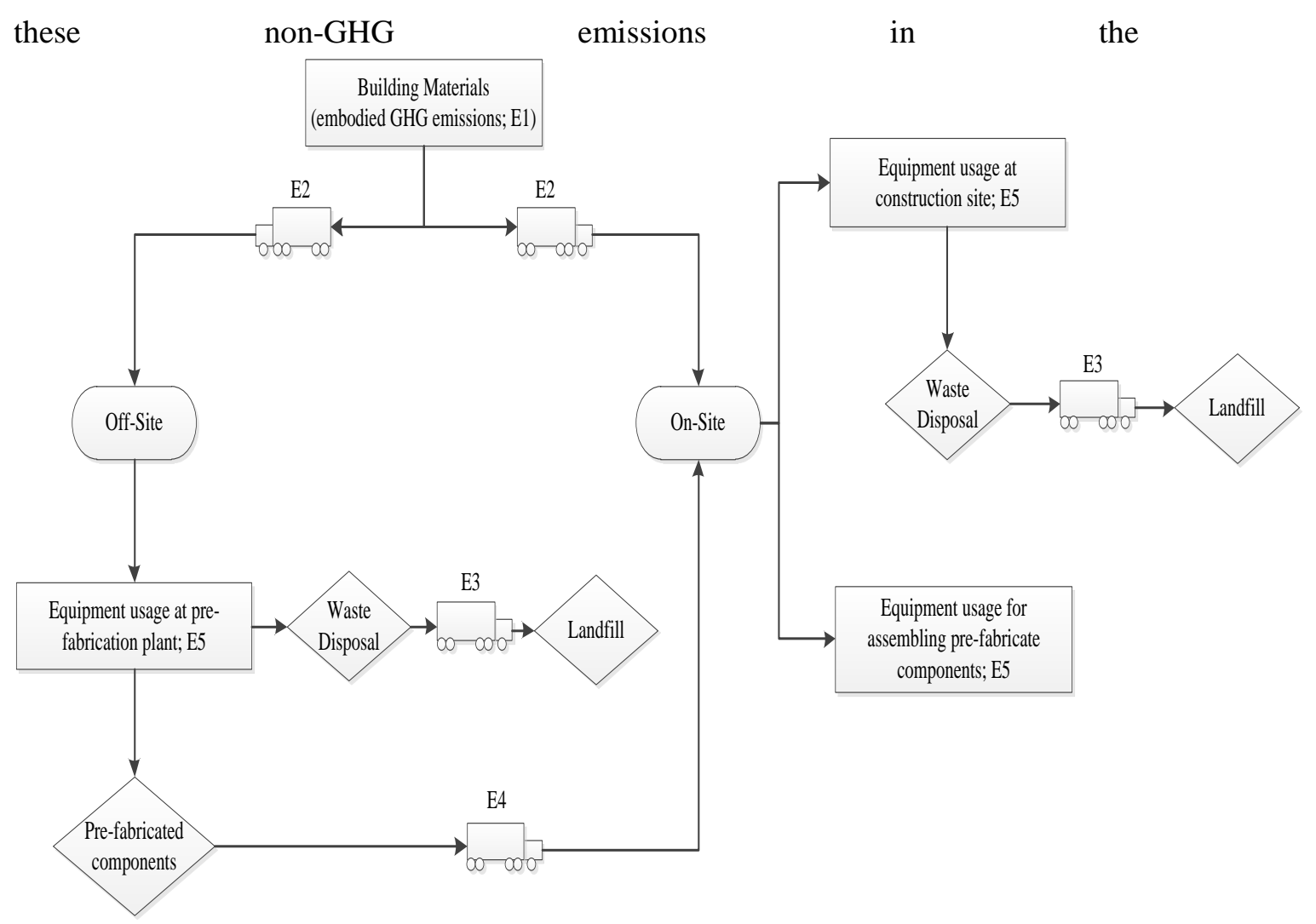

Figure 1. System boundary for the study

Table 1 shown below illustrates the emission substances considered for the study. 


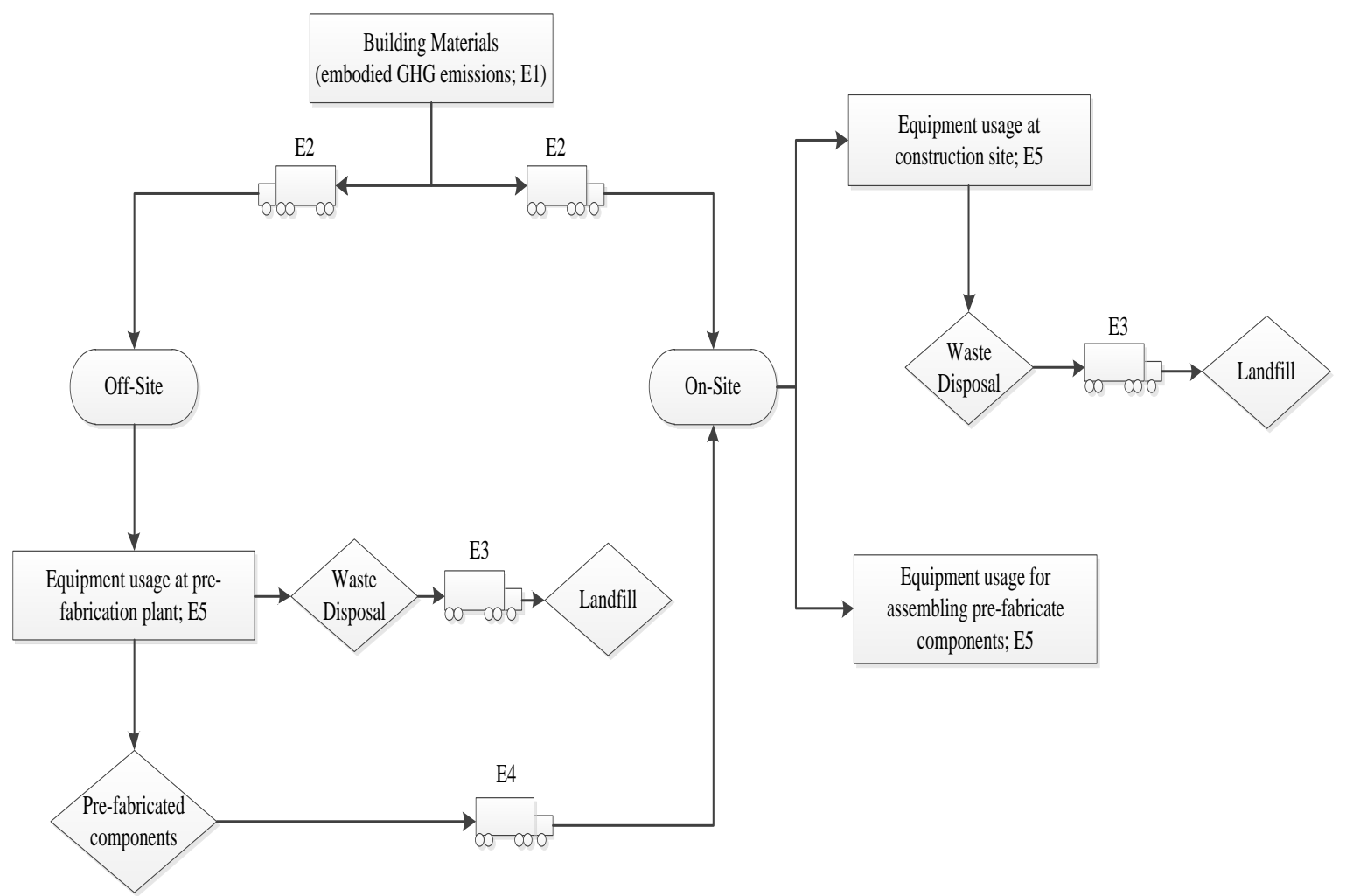

Figure 1. System boundary for the study

Table 1. Emission substances considered for the study

\begin{tabular}{|l|l|}
\hline Stage & Emission substance included \\
\hline Material stage & GHG \\
\hline Equipment usage stage & GHG, $\mathrm{CO}, \mathrm{NO}_{\mathrm{x}}, \mathrm{PM}$, hydro carbons $(\mathrm{HC})$, Sulphur dioxide $\left(\mathrm{SO}_{2}\right)$ \\
\hline Transportation stage & GHG, $\mathrm{CO}, \mathrm{NO}_{x}, \mathrm{NMVOC}$ \\
\hline
\end{tabular}

Impact assessment. The estimated environmental emissions are compared under five impact categories, i.e.., Global Warming Potential for 100 years (GWP 100), Acidification Potential (AP), Eutrophication Potential (EP), Photochemical Oxidant Formation Potential (POFP) and Human Toxicity Potential (HTP). These five impact categories are considered at global, regional and local perspectives based on the geographical location. The weighting factors for impact assessment at three different levels are obtained from a similar case study conducted in Australia (Sandanayake et al., 2016). The corresponding weighting factors are tabulated in Table 2. These weighting factors were developed using analytical hierarchy process (AHP).

Table 2. Weighting factors for impact assessment

\begin{tabular}{|l|c|c|c|}
\hline Impact category & Global & Regional & Local \\
\hline GWP 100 & 0.41 & 0.11 & 0.09 \\
\hline AP & 0.18 & 0.21 & 0.15 \\
\hline EP & 0.10 & 0.33 & 0.14 \\
\hline POFP & 0.20 & 0.21 & 0.30 \\
\hline HTP & 0.10 & 0.14 & 0.33 \\
\hline
\end{tabular}


The procedure for impacts calculation corresponds to four steps. Firstly, emission amounts are multiplied with the corresponding characterisation factor (in Table 3 ) to convert them to potential impacts $\left(\mathrm{P}_{\mathrm{i}}\right)$. Secondly, these potential impacts are normalised by using the standard Australian normalisation factors $(\mathrm{N})$. The $\mathrm{N}$ values are provided in Table 8 . These normalised impacts are then multiplied with the corresponding weighting factors to evaluate impacts at the three geographical levels. Finally the values can be effectively compared to obtain the relative importance of impacts for the three perspectives considered.

Table 3. Characterisation factors for the impacts

\begin{tabular}{|l|l|l|l|l|l|}
\hline Emission & $\mathrm{GWP}\left(\mathrm{CO}_{2}-\mathrm{e}\right)$ & $\mathrm{AP}\left(\mathrm{SO}_{2}-\mathrm{e}\right)$ & $\mathrm{EP}\left(\mathrm{PO}_{4}{ }^{3-}\right)$ & $\mathrm{POFP}\left(\mathrm{C}_{2} \mathrm{H}_{4}\right.$ eq $)$ & $\mathrm{HTP}\left(\mathrm{C}_{6} \mathrm{H}_{4} \mathrm{Cl}_{2}\right.$ eq $)$ \\
\hline $\mathrm{HC}$ & - & - & - & 1 & - \\
\hline $\mathrm{CO}$ & - & - & - & 0.3 & - \\
\hline $\mathrm{CO}_{2}$ & - & - & - & - & - \\
\hline $\mathrm{NO}_{\mathrm{x}}$ & - & 0.5 & 0.13 & - & 1.2 \\
\hline $\mathrm{PM}$ & - & - & - & - & 0.84 \\
\hline $\mathrm{SO}_{2}$ & - & 1.2 & - & 0.5 & 0.1 \\
\hline $\mathrm{NMVOC}$ & - & - & - & 1 & - \\
\hline
\end{tabular}

\section{CASE STUDY}

General project details. Two case studies were used to demonstrate a detailed comparative study in identifying the effect of using pre-fabrication on emissions at the construction stage of a building. Case study A is a semi-prefabrication construction project while case study B is a conventional construction project. Both case studies are of residential projects which are situated in the Central Business District (CBD) in Melbourne, Australia. These two case studies are chosen for comparison as they represent similar building characteristics. Since the building contractor is same it can be assumed that the construction methods and the project management skills remain similar. A summary of the general details of the two construction projects are shown in Table 4.

Table 4. General details of the two case studies

\begin{tabular}{|l|c|c|}
\hline Detail & Case study A & Case study B \\
\hline Total construction floor area (CFA) $\mathrm{m}^{2}$ & 70,200 & 69,360 \\
\hline Number of floors & 52 & 48 \\
\hline Project type & Residential & Residential \\
\hline Local environment & Urban & Urban \\
\hline Floor height $(\mathrm{m})$ & 3.3 & 3.3 \\
\hline
\end{tabular}

Data collection. Data collection can be explained based on materials, transportation and equipment usage. The major material quantities in Table 5 are collected through bill of quantities (BOQ) and daily receiving logs. Regular site visits were conducted to inspect the site progress and the daily reports provided from site engineers and site foremen. Distances travelled by transportation vehicles were obtained from route maps and other vehicle characteristics such as cumulative usage of the vehicle were obtained from the truck driver. Fuel combustion details, usage hours and machine characteristics are required to estimate emissions from equipment usage. The machine characteristics were obtained from machine technical data sheets while fuel combustion and usage hours of machines were obtained through on-site daily data collection. Total electricity usage of the construction site was obtained from the monthly bills. Table 6 illustrates the resource utilisation for both the case studies. 
Table 5. Material quantities and transportation distances

\begin{tabular}{|l|c|c|c|c|c|c|}
\hline \multirow{3}{*}{ Material } & \multicolumn{2}{|c|}{ Case study A (tons) } & \multirow{2}{*}{$\begin{array}{c}\text { Case study B } \\
\text { (tons) }\end{array}$} & & \multicolumn{3}{|c|}{ Transportation distance (km) } \\
\cline { 2 - 3 } \cline { 5 - 6 } & Pre-fab & In-situ & & Case study A & \multirow{2}{*}{ Case study B } \\
\hline Concrete & $5,466.45$ & $72,025.70$ & $68,427.8$ & 32 & 15 & 15 \\
\hline Steel & 358.85 & $3,437.8$ & $3,265.4$ & 32 & 15 & 15 \\
\hline Cement & - & 4145.48 & $3,987.8$ & - & 15 & 15 \\
\hline Sand & - & $21,485.5$ & $17,898.7$ & - & 15 & 15 \\
\hline Brick/blocks & - & $13,921.53$ & $10,028.9$ & - & 15 & 15 \\
\hline
\end{tabular}

Table 6. Resource utilisation for the two case studies

\begin{tabular}{|l|c|c|c|}
\hline \multirow{2}{*}{ Resource } & \multicolumn{2}{|c|}{ Case study A } & \multirow{2}{*}{ Case study B } \\
\cline { 2 - 3 } & Pre-fab & In-situ & 66,421 \\
\hline Diesel (L) & $5,020.87$ & $58,526.87$ & $646,953.81$ \\
\hline Electricity ( kWh) & $48,904.26$ & $570,063.43$ & \\
\hline
\end{tabular}

\section{RESULTS AND DISCUSSIONS}

GHG emissions comparison. The resulting GHG emissions for both the case studies are tabulated in Table 7. The comparative results indicate that the emission contribution due to transportation (E2, E3 and E4) is slightly higher for case study A (12.45\%) compared to case study B (11.83\%). The emission reduction contribution due to waste transportation remained insignificant. The results also signify that embodied emissions from materials govern the total GHG emissions with an emission percentage of over $82 \%$ for both case studies. The total emission reduction percentage (sum of final column in Table 7) counterbalance the emission increase due to prefabricated material transportation (16.5\%) which gives a total GHG emission reduction of $1.7 \%$.

Table 7. GHG emissions comparison for the two case studies

\begin{tabular}{|l|c|c|c|c|c|c|c|c|c|}
\hline \multirow{2}{*}{$\begin{array}{l}\text { Sourc } \\
\text { e }\end{array}$} & \multicolumn{4}{|c|}{ Case study A (tons) } & \multicolumn{3}{c|}{ Case study B (tons) } & Emission reduction & GHG \% \\
\cline { 2 - 10 } & Pre-fab & In-situ & Total & $\%$ & Total & $\%$ & B-A & proportion & reduction \\
\hline E1 & $1,322.7$ & $15,902.4$ & $17,225.1$ & 82.8 & 17498.1 & 82.34 & 272.9 & 62.3 & 1.6 \\
\hline E2 & 127.9 & 1858.2 & $1,896.3$ & 9.11 & 2015.0 & 9.48 & 118.7 & 27.1 & 5.9 \\
\hline E3 & 37.8 & 439.6 & 489.6 & 2.35 & 499.2 & 2.35 & 9.6 & 2.2 & 1.9 \\
\hline E4 & 72.3 & - & 72.3 & 0.35 & - & - & -72.3 & -16.5 & -16.5 \\
\hline E5 & 70.2 & $1,085$. & $1,128.4$ & 5.42 & 1237.8 & 5.82 & 82.6 & 25.0 & 8.8 \\
\hline Total & $\mathbf{1 6 3 0 . 9}$ & $\mathbf{1 9 , 1 8 0 . 2}$ & $\mathbf{2 0 , 8 1 1 . 4}$ & $\mathbf{1 0 0}$ & $\mathbf{2 1 , 2 5 0 . 1}$ & $\mathbf{1 0 0}$ & $\mathbf{4 3 8 . 5}$ & $\mathbf{1 0 0}$ & $\mathbf{1 . 7}$ \\
\hline
\end{tabular}

Non-GHG emissions comparison. The resulting emissions shown in Figure 2 signifies that $\mathrm{CO}$ and $\mathrm{NO}_{\mathrm{x}}$ emissions govern the non-GHG emissions while $\mathrm{HC}, \mathrm{PM}$ and $\mathrm{SO}_{2}$ are comparatively negligible. Moreover, it is also noted that non-GHG emissions are higher for case study A (semi-prefabrication) than case study B (conventional). This is due to the increased transportation (32 km compared to $15 \mathrm{~km}$ ) for pre-fabricated component transportation. However, these non-GHG emissions are significantly less compared to GHG emissions. Therefore it is important to evaluate the impacts to highlight the significance of non-GHG emissions. For the current comparative study this significance can be examined 
based on two aspects. One aspect is to check the total impact variation at global, regional and local level to identify the significance of non-GHG emissions. The other aspect is to check the impact of emission increase due to pre-fabricated material transportation at global, regional and local level. The following section explicitly discusses the impact assessment results.

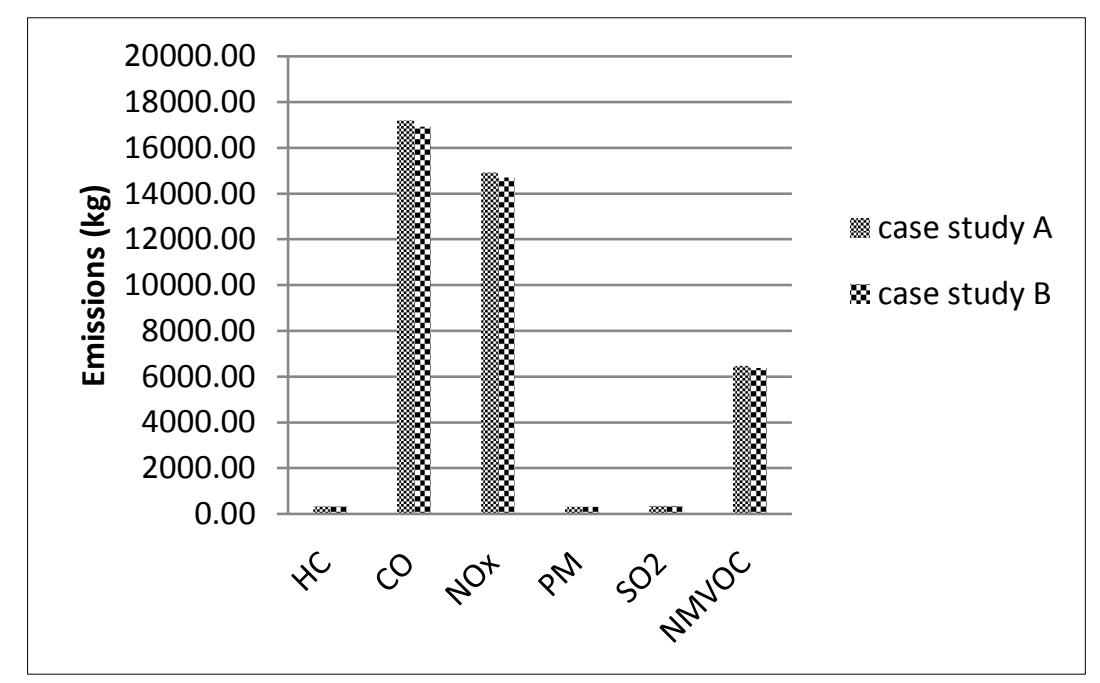

Figure 2. Direct non-GHG emissions for both the case studies

Impact assessment results. The normalised potential impacts $(\mathrm{Pi} / \mathrm{N})$ for both the case studies are shown in Table 8. To identify the relative significance of impacts, these potential impacts are multiplied by the weighting factors shown in Table 2 . The average relative importance of impacts for overall, global, regional and local perspective is shown in

Figure 3. The average potential impacts are calculated by obtaining the average of potential impacts for both the case studies. The overall perspective considers the relative importance of impacts without considering any specific geographic location while other three perspectives apply global, regional and local weighting factors to determine relative impacts. The resulting indices highlight that GWP 100 is the governing impact category for the four perspectives. However, this overwhelming relative importance of GWP $(86.78 \%)$ is significantly reduced to around 52\% at regional and local level with relatively higher contributions from EP $(21.74 \%)$ and POFP $(27.14 \%)$ impacts. This indicates that non-GHG emissions such as $\mathrm{CO}, \mathrm{NO}_{\mathrm{x}}, \mathrm{SO}_{2}$ and $\mathrm{NMVOC}$ are significant at regional and local level. Therefore, at short term level, these non-GHG emissions should also be given importance as GHG emissions.

Table 8. Normalised potential impacts $(\mathrm{Pi} / \mathrm{N})$ calculation for the two case studies

\begin{tabular}{|c|c|c|c|c|c|}
\hline \multirow{2}{*}{ Impact } & \multirow{2}{*}{$\begin{array}{c}\text { Normalisation } \\
\text { factors }(N)\end{array}$} & \multicolumn{2}{|c|}{ Case study A } & \multicolumn{2}{c|}{ Case study B } \\
\cline { 3 - 6 } & & $(\mathrm{Pi})$ & $\mathrm{Pi} / \mathrm{N}$ & $(\mathrm{Pi})$ & $\mathrm{Pi} / \mathrm{N}$ \\
\hline GWP & $621,000,000,000$ & $20,927,582.61$ & $3.3 \mathrm{E}-05$ & $21,249,097.8$ & $3.42 \mathrm{E}-05$ \\
\hline AP & $2,670,000,000$ & $7,868.33$ & $2.95 \mathrm{E}-06$ & $7,764.7$ & $2.96 \mathrm{E}-06$ \\
\hline EP & $416,000,000$ & $1,939.21$ & $4.66 \mathrm{E}-06$ & $1,910.6$ & $4.59 \mathrm{E}-06$ \\
\hline POFP & $1,610,000,000$ & $12,134.65$ & $7.54 \mathrm{E}-06$ & 5576.5 & $3.46 \mathrm{E}-06$ \\
\hline HTP & $69,600,000,000$ & $22,341.9$ & $3.21 \mathrm{E}-07$ & $17,935.45$ & $2.58 \mathrm{E}-07$ \\
\hline
\end{tabular}




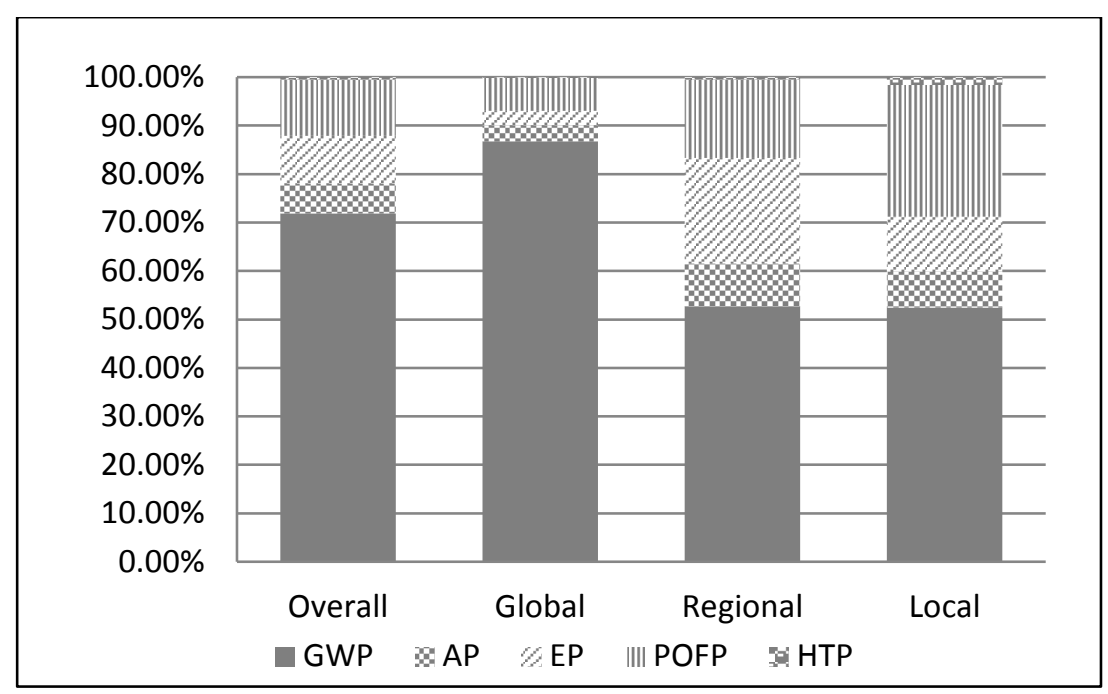

Figure 3. Average relative importance of impacts for both the case studies

The next option is to compare the relative importance of impacts for both the case studies separately to identify the effect of increase of emissions due to pre-fabricated components transportation. The corresponding results are shown in Error! Reference source not found.. HTP impact category is not considered due to its negligible significance for all the perspectives.

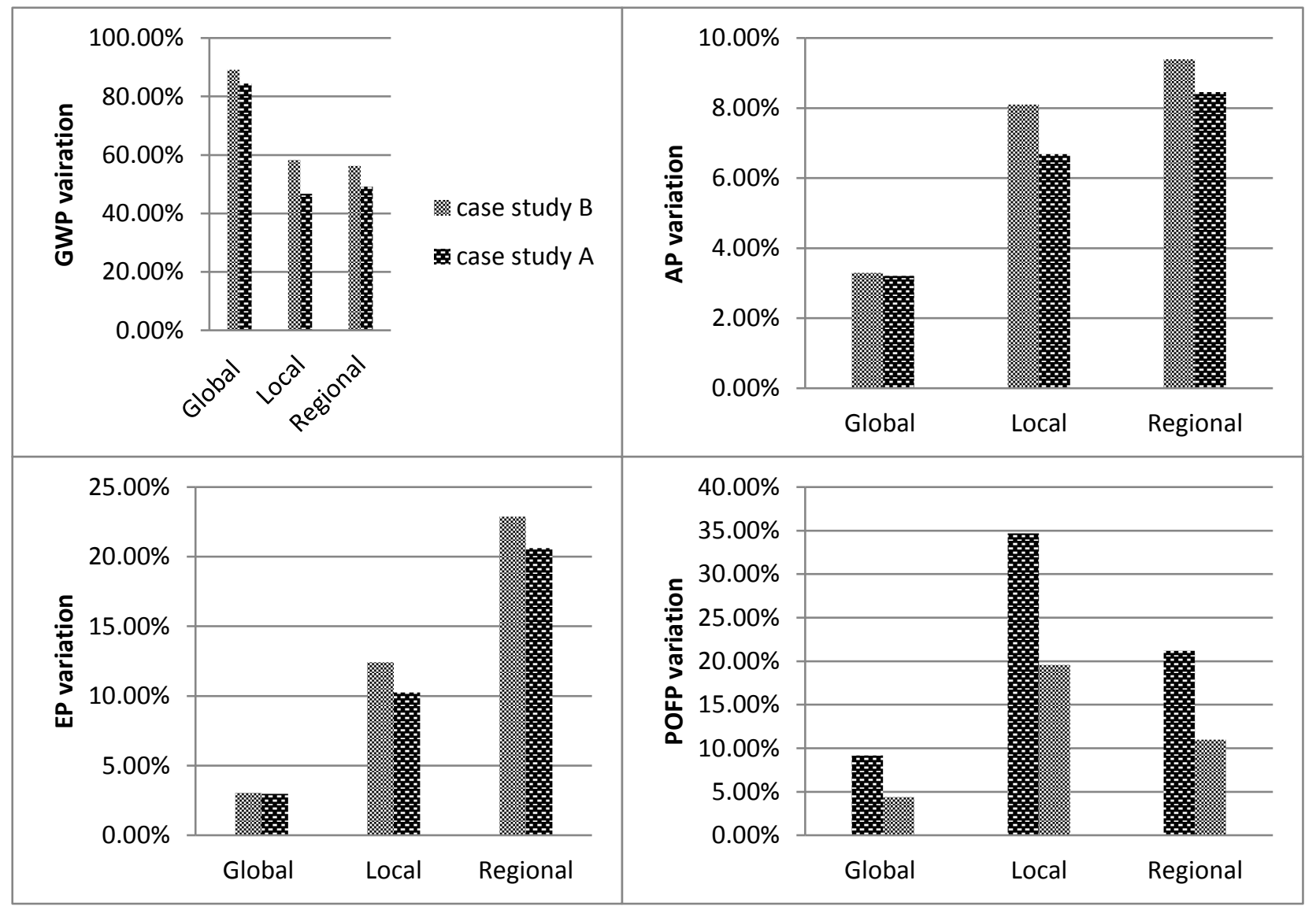

Figure 4. Relative importance of impacts variation for case studies A \& B 
These results signify that the relative importance of GWP, AP and EP impacts are comparatively high for case study B (conventional) than case study A (semi-prefabrication). However for POFP, the relative impact importance at all the three perspectives is high for case study $\mathrm{A} . \mathrm{HC}, \mathrm{CO}, \mathrm{SO}_{2}$ and $\mathrm{NMVOC}$ contribute to the POFP impact. This observation signifies that non-GHG emissions due to transportation are much significant for case study A. Moreover, it is also observed that the difference of relative importance in case studies A and B for POFP impact is increased from global to local perspectives. This observation implies that adopting pre-fabrication may enforce relatively high POFP impacts at local and regional level. However the effect of other impacts such as GWP, AP and EP seems to be reducing from global to regional and local perspectives. Therefore adopting pre-fabrication method is embrace less impacts for GWP, AP and POFP at regional and local perspective.

\section{CONCLUSIONS AND SUGGESTIONS}

The construction stage of a building involves both GHG and non-GHG emissions due to embodied emissions from materials, emissions due to equipment usage and transportation. Previous studies have shown using different materials and construction methods can reduce emissions at the construction stage. The study is intended to compare emissions at the construction stage of a building using two case studies of conventional construction and a semi-prefabrication construction projects. The estimated emissions were then utilised to compare relative impacts at three geographical aspects namely global, regional and local perspectives.

A total GHG emission distribution of $82.8 \%, 11.8 \%$ and $5.4 \%$ was observed in case study A for embodied emissions from materials, emissions from transportation and equipment usage respectively. For case study $\mathrm{B}$, this distribution was recorded as $82.3 \%, 11.8 \%$ and $5.8 \%$ for embodied emissions from materials, emissions from transportation and equipment usage respectively. It was also observed that a GHG emission reduction of $1.7 \%$ can be obtained by adopting pre-fabrication during the construction stage. $\mathrm{CO}$ and $\mathrm{NO}_{\mathrm{x}}$ emissions are significant for non-GHG emissions. These non-GHG emissions are higher for case study A due to the increase of pre-fabricated components transportation.

The impact assessment results concluded that GWP 100 remained the highest impact category for all the three perspectives. The overpowering GWP contribution of around $86 \%$ is reduced to around $52 \%$ at regional and local perspectives with relatively high contributions from POFP and EP. This observation also highlights that non-GHG emissions such as $\mathrm{CO}, \mathrm{SO}_{2}$ and $\mathrm{NMVOC}$ are significant at regional and local level. Moreover, the relative impact difference for POFP between case study A and B is increased at regional and local perspectives. This also signifies that direct non-GHG emissions are significant at regional and local level. However, this difference remained insignificant for other impact categories. Therefore, it can be concluded that adopting pre-fabrication can reduce GHG emissions at the construction stage of a building. However, in doing so, effective resource planning and allocation should be executed to minimise non-GHG emissions due to increased transportation effects.

The results obtained in the study are highly case specific. Therefore, further generic studies encouraged to draw more conclusive results. The results of the case study can be effectively used to identify emission reduction possibilities by adopting different construction methods and techniques. Further studies can also be undertaken to identify the options and methods to minimise the direct non-GHG emissions from equipment usage and transportation.

\section{REFERENCES}

DIMOUDI, A. \& TOMPA, C. 2008. Energy and environmental indicators related to construction of office buildings. Resources, Conservation and Recycling, 53, 86-95. 
FREY, H. C., RASDORF, W. \& LEWIS, P. 2010. Comprehensive field study of fuel use and emissions of nonroad diesel construction equipment. Transportation Research Record: Journal of the Transportation Research Board, 2158, 69-76.

GUGGEMOS, A. A. 2003. Environmental impacts of on-site construction processes: Focus on structural frames. University of California, Berkeley.

GUGGEMOS, A. A. \& HORVATH, A. 2005. Comparison of environmental effects of steel-and concreteframed buildings. Journal of Infrastructure Systems, 11, 93-101.

GUGGEMOS, A. A. \& HORVATH, A. 2006. Decision-support tool for assessing the environmental effects of constructing commercial buildings. Journal of Architectural Engineering, 12, 187-195.

HONG, J., SHEN, G. Q., FENG, Y., LAU, W. S.-T. \& MAO, C. 2015. Greenhouse gas emissions during the construction phase of a building: a case study in China. Journal of Cleaner Production, 103, 249259.

MAO, C., SHEN, Q., SHEN, L. \& TANG, L. 2013. Comparative study of greenhouse gas emissions between off-site prefabrication and conventional construction methods: Two case studies of residential projects. Energy and Buildings, 66, 165-176.

SAMARAS, Z. \& ZIEROCK, K.-H. 1995. Off-road vehicles: a comparison of emissions with those from road transport. Science of the total environment, 169, 249-255.

SANDANAYAKE, M., ZHANG, G. \& SETUNGE, S. 2016. Environmental emissions at foundation construction stage of buildings - Two case studies. Building and Environment, 95, 189-198.

SANDANAYAKE, M., ZHANG, G., SETUNGE, S. \& THOMAS, C. 2015. Environmental Emissions of Construction Equipment Usage in Pile Foundation Construction Process-A Case Study. In: SHEN, L., YE, K. \& MAO, C. (eds.) Proceedings of the 19th International Symposium on Advancement of Construction Management and Real Estate. Springer Berlin Heidelberg.

WONG, P. S., LACARRUBA, N. \& BRAY, A. 2012. Can carbon tax push the Australian construction sector towards self-regulation?-Lessons learned from the European Union experiences. Journal of Legal Affairs and Dispute Resolution in Engineering and Construction.

YAN, H., SHEN, Q., FAN, L. C., WANG, Y. \& ZHANG, L. 2010a. Greenhouse gas emissions in building construction: A case study of One Peking in Hong Kong. Building and Environment, 45, 949955.

YAN, H., SHEN, Q., FAN, L. C. H., WANG, Y. \& ZHANG, L. 2010b. Greenhouse gas emissions in building construction: A case study of One Peking in Hong Kong. Building and Environment, 45, 949955. 